\title{
Laryngeal Cancer pN2a TNM Finding v8
}

National Cancer Institute

\section{Source}

National Cancer Institute. Laryngeal Cancer pN2a TNM Finding v8. NCI Thesaurus. Code C133144.

Laryngeal cancer with metastasis in a single ipsilateral or contralateral lymph node, $3 \mathrm{~cm}$ or less in greatest dimension and $\mathrm{ENE}(+)$; or metastasis in a single ipsilateral lymph node, more than $3 \mathrm{~cm}$ but not more than $6 \mathrm{~cm}$ in greatest dimension and ENE(-). (from AJCC 8th Ed.) 